\title{
CIDADES EDUCADORAS: UM ESTADO DA ARTE ENTRE 1990 E 2020 E A RELAÇÃO COM A EDUCAÇÃO FORMAL
}

\author{
EDUCATING CITIES: A STATE- OF- THE- ART BETWEEN 1990 AND 2020 AND THE RELATIONSHIP \\ WITH FORMAL EDUCATION \\ CIUDADES EDUCADORAS: UN ESTADO DEL ARTE ENTRE 1990 Y 2020 Y LA RELACIÓN CON LA \\ EDUCACIÓN FORMAL
}

\begin{abstract}
Maria Sílvia Bacila
Doutora em Educação pela pontifícia Universidade Católica do Paraná (PUCPR). Professora Associada ao Departamento de Educação da UTFPR. Gestora da Secretaria Municipal da Educação de Curitiba/PR- Brasil. ORCID: https://orcid.org/0000-0003-0953-7106, e-mail: silvia.bacila@gmail.com
\end{abstract}

\section{RESUMO}

Esta investigação discute as produções bibliográficas sobre cidades educadoras, segundo o movimento preconizado pela Associação Internacional de Cidades Educadoras (AICE), e suas relações com a educação formal, não formal e informal. Para tal, identificou-se a produção bibliográfica em livros publicados em língua portuguesa entre 1990 e 2020. A pesquisa é um estudo exploratório (TRIVIÑOS, 2006), do tipo estado da arte, pois visa mapear esta produção para responder às aproximações e aos distanciamentos com a temática educacional (ROMANOWSKI; ENS, 2006). A coleta de dados ocorreu por meio de levantamento bibliográfico e a busca das obras foi realizada em sites de e-commerce, com os descritores "cidade educadora" e "cidades educadoras". Encontraram-se 11 obras publicadas em língua portuguesa - duas provenientes de Portugal. As obras originárias das editoras portuguesas apresentaram uma expressiva familiaridade com o movimento da AICE de Barcelona; já os outros trabalhos aludem a perspectivas formais ou não formais da educação. No entanto, um dos livros distancia-se do movimento da AICE, embora contribua com as pesquisas sobre os sujeitos e a vida na cidade. Para investigações futuras, sugere-se o levantamento de outras questões, provenientes das obras analisadas.

Palavras-chave: Cidades Educadoras; Educação Formal; Educação Não Formal.

\begin{abstract}
This investigation discusses the bibliographic productions on educating cities, according to the movement advocated by the International Association of Educating Cities (IAEC), and its relations with formal, nonformal, and informal education. For this purpose, it identified the bibliographic production in books published in Portuguese, between 1990 and 2020. The research is an exploratory study (TRIVIÑOS, 2006) of the stateof-the-art type, as it aims to map this production seeking to respond to the approximations and distances with the educational theme (ROMANOWSKI; ENS, 2006). The data collection technique was carried out through a bibliographical survey and the search for the works was performed on e-commerce sites, with the descriptors "educating city" and "educating cities". Eleven works published in Portuguese were found two of them from Portugal. The works from Portuguese publishers presented great familiarity with the IAEC movement in Barcelona; the other works allude to formal or non-formal perspectives on education. However, one of the books distances itself from the IAEC movement, although it contributes to the research of subjects and city life. For future investigations, it is suggested to raise other questions, arising from the analyzed works.
\end{abstract}

Keywords: Educating Cities; Formal Education; Non-Formal Education. 
Esta investigación analiza las producciones bibliográficas sobre ciudades educadoras, según el movimiento que propugna la Asociación Internacional de Ciudades Educadoras (AICE) y sus relaciones con la educación formal, no formal e informal. Para ello, identifica la producción bibliográfica concentrada en libros editados en portugués entre los años 1990 y 2020. La investigación es un estudio exploratorio (TRIVIÑOS, 2006), del tipo estado del arte, que pretende mapear la producción académica buscando dar respuesta a las aproximaciones y distancias con el tema educativo (ROMANOWSKI; ENS, 2006). La recolección de datos se hizo en medios bibliográficos y la búsqueda de las obras se realizó en sitios de comercio electrónico, con los descriptores "ciudad educadora" y "ciudades educadoras". Se encontraron once obras publicadas en portugués, dos de ellas provenientes de Portugal. Las obras originales de las editoras portuguesas muestran mucha familiaridad con el movimiento AICE de Barcelona; los demás trabajos aluden a perspectivas formales o no formales de la educación. Sin embargo, uno de los libros se aleja del movimiento de la AICE, aunque contribuye con las investigaciones sobre los sujetos y la vida en la ciudad. Para investigaciones futuras, se sugiere atender otras cuestiones, provenientes de las mismas obras analizadas.

Palabras-clave: Ciudades Educadoras; Educación Formal; Educación No Formal.

\section{INTRODUÇÃO}

As cidades são locais públicos pertencentes a todos os seus cidadãos e, consequentemente, que a vivem na sua complexidade. Cada cidade, com seus equipamentos, seus habitantes, suas dificuldades e suas superações, constitui-se como uma experiência ímpar para aqueles que nela vivem.

A organização dos seus espaços molda a forma de dirigir dos munícipes; ademais, a participação dos habitantes na organização dos seus territórios também é demarcada histórica e culturalmente. Essa relação dialética e suas possibilidades vêm ganhando espaço de discussão, formação e relação acadêmica. O movimento demarcado pela Associação Internacional de Cidades Educadoras, nascido em Barcelona na década de 1990, é o exemplo da força e da concretude da municipalidade na vida dos sujeitos.

Jan Gehl (2015, p. 11) afirma que "cidades assim como livros podem ser lidos"; isto posto, esta investigação convida à leitura das cidades que se propuseram a ser lidas, aos sujeitos pesquisadores que se envolveram com a temática dos territórios educativos e sua produção bibliográfica.

\section{Metodologia}

Este texto tem por objetivo analisar a produção bibliográfica entre 1990 e 2020 das obras publicadas em língua portuguesa sobre cidades educadoras. Trata-se de uma pesquisa bibliográfica que visa contribuir com a temática, especialmente no seu fortalecimento no que tange ao seu registro científico oriundo do movimento de cidades educadoras nascido na cidade de Barcelona, em 1990 — como supracitado. Tal movimento 
é fruto das políticas internacionais que tinham como propósito a garantia, sobretudo, dos direitos humanos e a pertença dos sujeitos em suas cidades; ou seja, garantir a municipalidade como território educativo.

Com base nos estudos de cidades educadoras, é possível identificar três grandes eixos relacionados à perspectiva educativa, com ações que são eminentemente destinadas às relações formais da educação, aquelas que transitam na educação não formal e as que são oriundas da educação informal. Este texto pretende analisar as aproximações desta produção bibliográfica, com o recorte entre 1990 e 2020, com a educação formal; ou seja, com as produções que denotam práticas sistemáticas educacionais planejadas e executadas dentro de um sistema em seus territórios educacionais.

Identificaram-se 11 livros em língua portuguesa, editados no Brasil e em Portugal, com o descritor "Cidade Educadora" ou "Cidades Educadoras". A busca ocorreu em sites relacionados à compra por e-commerce, tanto para livros novos quanto usados, sendo a principal referência a plataforma Estante Virtual. A procura aconteceu, essencialmente, em plataformas virtuais, devido à pandemia decorrente do coronavírus, em que a pesquisa em locais públicos ficou limitada. Todos os volumes foram adquiridos para a leitura e análise dos documentos escritos.

A questão norteadora dessa investigação trata do seguinte aspecto: o que dizem os livros publicados entre 1990 e 2020 com os descritores "cidade educadora" ou "cidades educadoras"? Objetivou-se realizar um levantamento de obras com esses descritores e compreender a sua vocação relacionada aos princípios do movimento, preconizado pela Associação Internacional de Cidades Educadoras, com sede em Barcelona, responsável pelo suporte e pelo monitoramento das cidades educadoras no mundo.

\section{Resultados}

O movimento de Cidades Educadoras foi inaugurado em 1990, com alicerce no I Congresso Internacional de Cidades Educadoras, ocorrido na cidade de Barcelona (Espanha), quando um pequeno conjunto de cidades - ali representadas por seus governos locais - estabeleceu um pacto com o objetivo comum de trabalhar juntas em projetos e ações para aquilatar a qualidade de vida dos seus habitantes. A premissa era que a participação de cada munícipe seria o alicerce para a pertença à cidade e sua evolução. Elaborou-se a primeira Carta de Cidades Educadoras, contendo 20 princípios para esse 
movimento; posteriormente, em 1994, esta iniciativa foi formalizada com o III Congresso Internacional em Bolonha.

O arquiteto Jan Gehl (2015), em seu livro Cidades para pessoas, manifesta uma premissa do direcionamento da Associação Internacional de Cidades Educadoras, sem uma relação formal com essa entidade, no entanto, com intensa familiaridade teórica ao movimento, "Nós moldamos as cidades, e elas nos moldam” (p. 11). Assim como as cidades imprimem suas marcas nos sujeitos que nelas habitam, esses também modulam seus territórios, provocam mudanças, determinam as relações históricas e culturais entre cidades, territórios e sujeitos.

Permitir que uma criança se aproprie de sua cidade, seu uso, seus espaços, sua escala de observação, seus problemas e, sobretudo, proponha soluções com voz ativa, partícipe, cidadã, é uma das prerrogativas da Associação de Cidades Educadoras e suas aproximadamente 500 cidades adjuntas no mundo, bem como delinear a análise das obras dessa investigação.

As obras encontradas em ordem cronológica foram as seguintes:

- ZAINKO, Maria Amelia Sabbag (org.). Cidades educadoras. Curitiba: Editora da UFPR, 1997.

- CABALLO VILLAR, Maria Belén. A cidade educadora. Lisboa: Instituto Piaget, 2001. (Coleção O Homem e a Cidade).

- CARRANO, Paulo César. Juventudes e cidades educadoras. Petrópolis: Vozes, 2003.

- GÓMEZ-GRANELL, Carmen; VILA, Ignacio (org.). A cidade como projeto educativo. Trad. Daisy Vaz de Moraes. Porto Alegre: Artmed, 2003.

- GADOTTI, Moacir; PADILHA, Paulo Roberto; CABEZUDO, Alicia (org.). Cidade educadora: princípios e experiências. São Paulo: Cortez: Instituto Paulo Freire; Buenos Aires: Ciudades Educadoras America Latina, 2004.

- TOLEDO, Leslie; FLORES, Maria Luiza Rodrigues; CONZATTI, Marli (org.). Cidade educadora: a experiência de Porto Alegre. São Paulo: Cortez: Instituto Paulo Freire; Buenos Aires: Ciudades Educadoras America Latina, 2004. (Coleção cidades educadoras).

- PINTO, Fernando Cabral. Cidadania, sistema educativo e cidade educadora. Lisboa: Instituto Piaget, 2004. (Coleção Horizontes Pedagógicos). 
- BIASOTTO, Wilson Valentim. Edificando a nossa cidade educadora. Dourados: Nicanor Coelho Editor, 2006.

- MORIGI, Valter. Cidades educadoras: possibilidades de novas políticas públicas para reinventar a democracia. Porto Alegre: Sulina, 2016.

- MARTINEZ, Roberto. A educação ambiental na cidade educadora. Curitiba: Appris Editora, 2017.

- ALVES, Alceli Ribeiro; BRANDENBURG, Elena Justen. Cidades educadoras: um olhar acerca da cidade que educa. Curitiba: InterSaberes, 2018.

Indagou-se, primeiramente, qual o país de origem da obra, em termos de publicação, pois, como Barcelona foi o berço do movimento Cidades Educadoras, muitos textos são escritos em língua espanhola e retratam experiências dessa cidade legitimamente significativas para o mundo. Contudo, com três décadas de existência, a AICE ganhou cidades signatárias de todos os continentes e, consequentemente, o registro e a produção acadêmica devem ter sido também nas tensões global e local, como já se vive nas demais dimensões da geração do conhecimento.

Nesta investigação, buscou-se investigar a origem das obras e, assim, construir o Gráfico 1, o qual informa sobre os países de origem das editoras que as publicaram, conforme a seguir:

Gráfico 1 - País de origem das obras

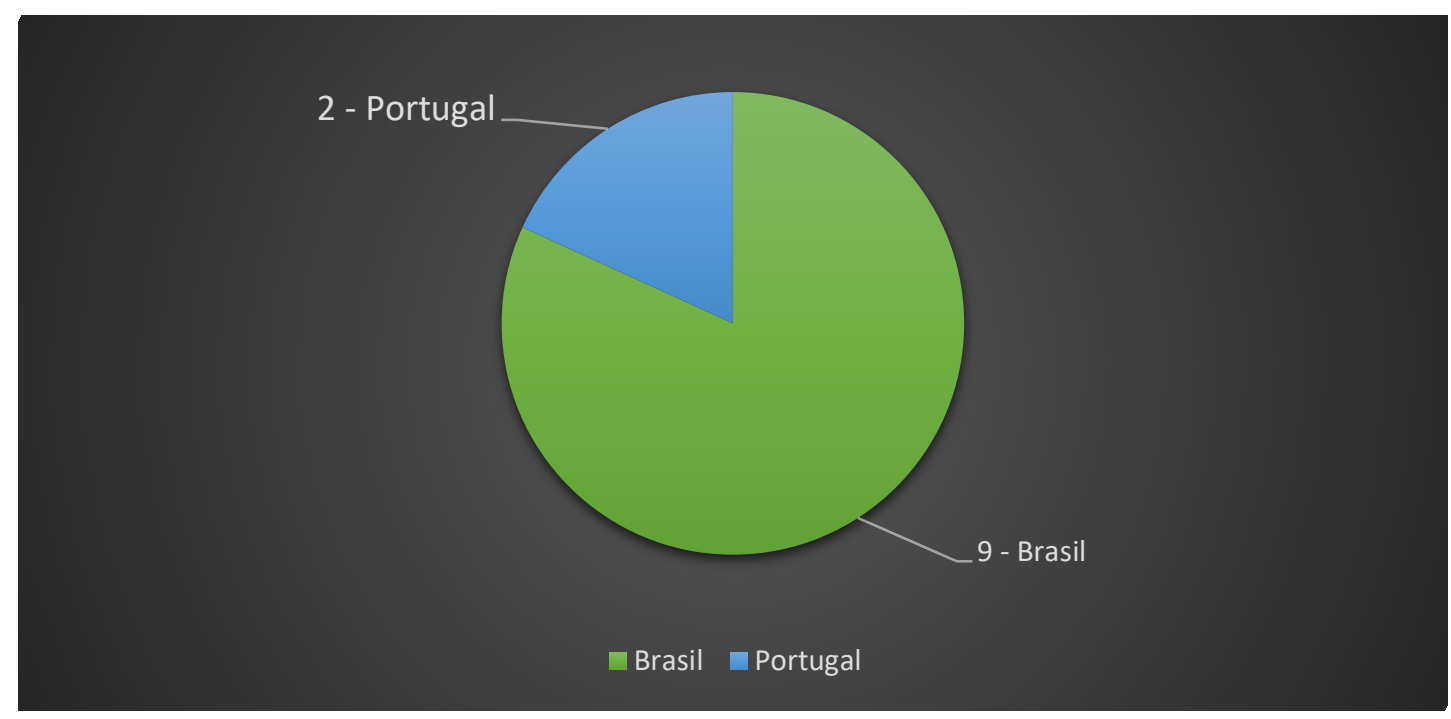

Fonte: informações obtidas pela pesquisa. 
Dos 11 livros analisados, nove foram publicados no Brasil e dois em Portugal, pela Editora Instituto Jean Piaget. Destarte, algumas das obras brasileiras fazerem alusão às experiências espanholas e as portuguesas são marcos de referência do modelo espanhol sobre cidades educadoras, tanto no aspecto vivencial das ações, em distintos segmentos da cidade, quanto na perspectiva filosófica.

A obra de Caballo Villar (2001) contribui com análises determinantes para a compreensão do movimento das cidades, em sua vocação educadora. Destaca as etapas evolutivas da cidade educadora e enaltece a primeira delas, nos anos 70 , quando se agudiza na sociedade a consciência da necessidade de uma população culta. Nessa direção, a responsabilização recai, fundamentalmente, sobre a escola; no entanto, a crítica entre as relações da escola com a comunidade foi importante para se chegar à segunda etapa evolutiva, na próxima década.

Admite-se que, a partir dos anos 80 , inicia-se uma forte crítica ao que se denomina "escolacêntrica” (CABALLO VILAR, 2001, p. 24), melhor traduzido como escolacentrismo, neologismo que traduz toda a responsabilização da educação para a escola e, assim, colocar a cidade à disposição de todos os cidadãos, ou melhor ainda, segundo Alfieri (1994), apud Caballo Villar (2001, p. 24), "A cidade deve pôr-se à disposição de todos os cidadãos e não só daqueles que a quem a escola permite".

A terceira fase define-se a partir do efetivo amadurecimento das relações entre escola e comunidade, ou seja, há um progressivo entendimento da complexidade nas relações escola-comunidade no momento em que se define um projeto educativo territorial entre os diferentes agentes educativos implicados. A criança se torna protagonista desse processo, portanto, não é mais quem recebe passivamente as ações formativas, mas delas participa, opina, constrói, produz socialmente o conhecimento. Para o adulto partícipe dessa comunidade, desse território educativo, oferece possibilidades reais de protagonizar sua construção em um coletivo adulto-criança.

Um conceito que vem à baila é o questionamento do uso de cidade educadora e não o de rural educador. Porto (1991 apud CABALLO VILLAR, 2001), questiona o uso do termo cidade educadora e admite que a vida de mais da metade da população europeia se dá no meio urbano, além de entender que a cidade organiza outros territórios.

A cidade, os seus recursos, a sua economia, a sua organização, a sua política definem a vida de espaços que superam em muito o território da cidade em si. Seguindo essa 
concepção, a obra de Cabral Pinto (2004) destaca o direito à educação, após a reforma constitucional do Estado espanhol.

Destaca o reordenamento jurídico a partir da Constituição de 1978 e, em seu artigo 1. ${ }^{\circ}$, o Estado ficou obrigado a garantir o exercício dos direitos humanos, a respeitar autonomia das comunidades regionais, a promover o progresso da cultura e da economia, a estabelecer uma sociedade democrática avançada e a fomentar a paz e a cooperação entre todos os povos da Terra. A educação terá seus fins próprios vinculados a essa concepção constitucional.

Confere ao movimento das cidades educadoras legitimidade e atesta:

\begin{abstract}
Alarga-se, consequentemente, o conceito de educação. Educação é formação de todos, em todas as oportunidades e espaços do quotidiano, ao longo de toda a vida. Emerge, assim, a importância da educação não formal e informal, com a subsequente relativização da educação formal. A escola passa a ser todo o território; a educação torna-se efetivamente permanente: educação para uma vida cultural e socialmente multiactiva em qualquer fase do percurso da vida dos indivíduos (CABRAL PINTO, 2004, p. 151).
\end{abstract}

Admite-se que a ideia de cidade educadora nasce de uma utopia; no entanto, à medida que a humanidade passa da heteronomia para a autonomia, os municípios se tornam efetivamente autárquicos, permitindo a auto-organização. Nesse caso, a utopia abandona a sua dimensão transcendental e assume o protagonismo holístico e histórico para ser humanamente realizada.

As duas obras publicadas pelo Instituto Piaget têm ampla familiaridade com a Associação Internacional de Cidades Educadoras, legitimam o movimento e conceitualizam as temáticas originárias da cidade de Barcelona, o que amplia as possibilidades de compreensão e apreensão por outros territórios.

A investigação seguiu inquirindo a relação das obras com o movimento da AICE, o que resultou nos dados ilustrados pelo Gráfico 2: 


\section{Gráfico 2 - Relação com a AICE}

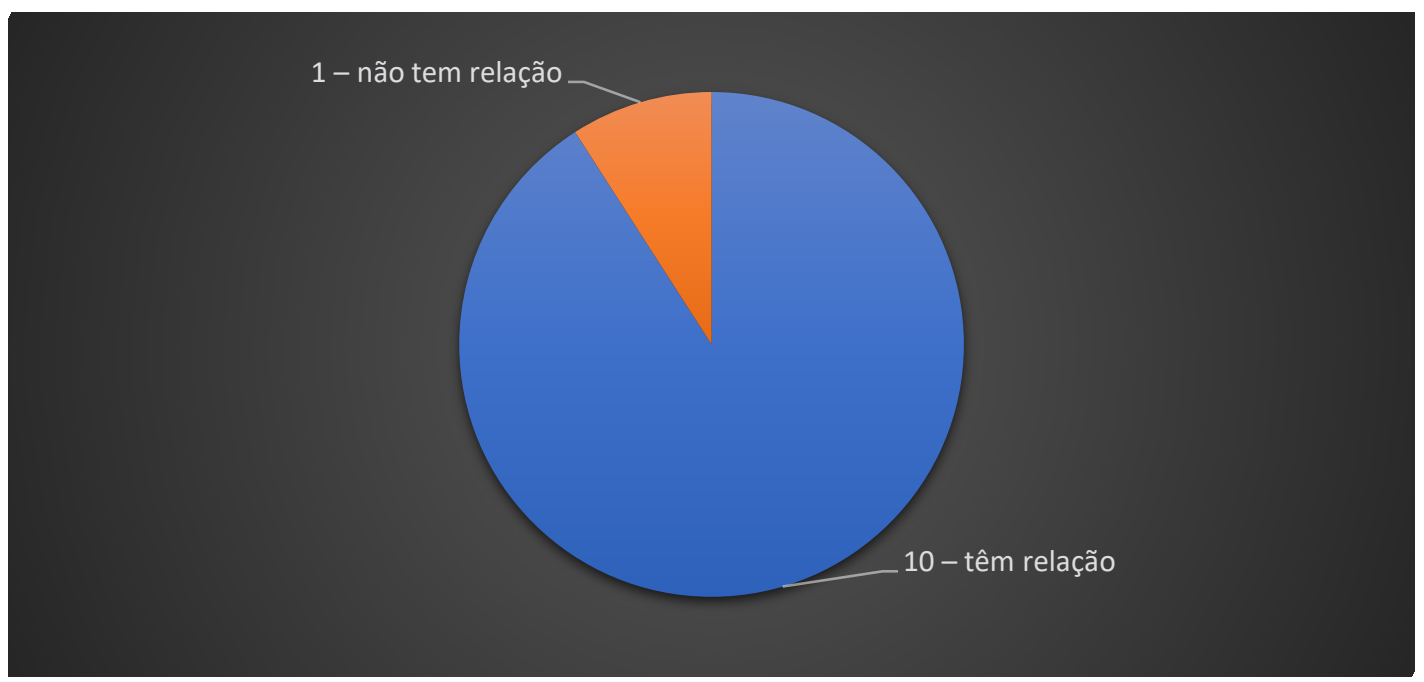

Fonte: informações obtidas pela pesquisa.

Das 11 obras analisadas, apenas uma não menciona elementos da Carta de Cidades Educadoras, como também não faz alusão à Associação Internacional de Cidades Educadoras. Trata-se da pesquisa de Carrano (2003), que apesar de não fazer alusão ao movimento, tem profunda reflexão sobre o sentido das juventudes e seu protagonismo para erigir as cidades educadoras.

O estudo destaca, também, os tipos de cidades ao longo da história, suas mudanças e a formação da subjetividade.

Paralelamente a essas mudanças, analisa a corporicidade moderna e industrial capitalista como um conjunto de transformações científicas, econômicas, sociais e políticas, que impulsionaram o surgimento de uma sociedade radicalmente distinta das antigas sociedades medievais, particularmente naquilo que se refere à organização das cidades e às práticas de controle corporal.

Nesta obra, emerge um termo que sintetiza o entrelaçamento do movimento dos corpos/sujeitos na vida em sua perspectiva holística na municipalidade, advindo da concepção grega de pólis. "A noção de corporicidade foi sugerida como uma possibilidade para a compreensão dos movimentos que os corpos/sujeitos estabelecem na histórica complexificação da organização social das cidades." (CARRANO, 2003, p. 12).

Analisou-se, também, nas obras analisadas, a relação dessas com a educação formal, não formal e informal. O Gráfico 3 indica a familiaridade das obras com os eixos formal e não formal. 
Gráfico 3 - Relações das obras com a educação formal e não formal

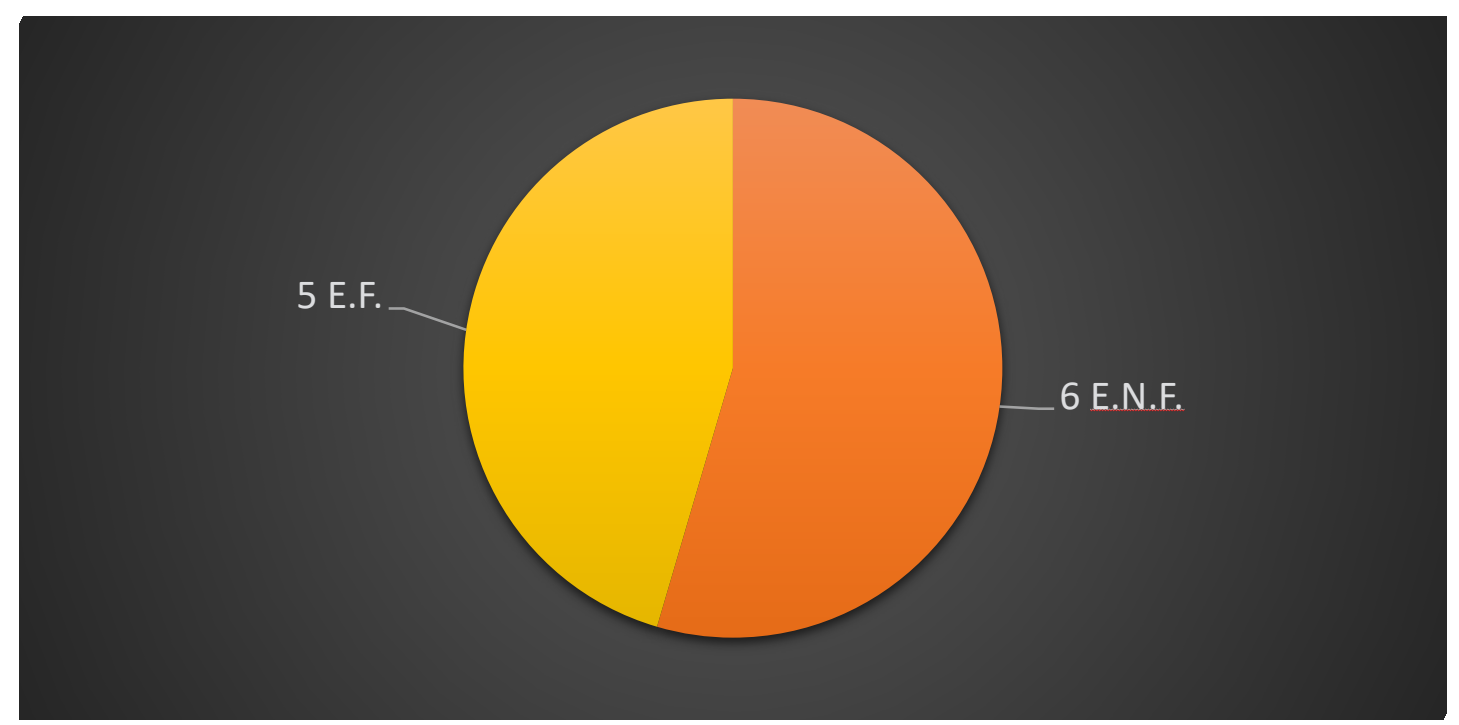

Fonte: informações obtidas pela pesquisa.

A educação formal é aquela desenvolvida no ambiente escolar, na sala de aula, com conteúdo estruturado. Já a educação não formal ocorre fora da escola, em museus, espaços públicos, bairros, ruas, enquanto a educação informal manifesta-se sem intencionalidade, no processo de socialização, em grupos religiosos, mídia, intercâmbios familiares.

As obras que se destacam com a proximidade do eixo da pergunta norteadora dessa pesquisa são as de Gomez-Granell e Vila (2003), Toledo, Flores e Conzatti (2004), Gadotti, Padilha e Cabezudo (2004), Martinez (2017) e Alves e Brandenburg (2018).

Para Gómez-Granell e Vila (2003), a ideia que se defende é a de que a educação é um elemento estratégico para a existência e o bom funcionamento da nossa sociedade. Isso nos faz signatários de um discurso sobre a relevância da educação, o que nos leva a pensar e, consequentemente, a repensar a relação entre a educação e as cidades, entre a escola e o território.

Assim, os autores questionam: há uma série de aspectos no centro dessa concepção? Quais seriam eles? Destacam também: a relação da sociedade do conhecimento e suas fortes implicações educativas; o entendimento de que as mudanças não são um continuum e necessitam ser compreendidas como autênticas revoluções sociais, culturais e institucionais; e, por fim, o entendimento de que a educação não é uma etapa da vida, mas faz parte de toda a vida. 
Toledo, Flores e Conzatti (2004) relatam experiências bem-sucedidas na cidade de Porto Alegre, cidade que já foi signatária ao movimento da Associação Internacional de Cidades Educadoras. Deixou um legado de experiências bem-sucedidas na área de cidades educadoras para sua cidade e as coirmãs, que entraram paralela e posteriormente à sua passagem pelo grupo.

A obra avulta o desempenho da educação na construção da cidadania planetária e, ao mesmo tempo, a relevância do poder local na transformação da sociedade. Evoca-se Paulo Freire na perspectiva de que é preciso pensar e agir em rede, na qual todos podem caber. "Não podemos mudar o mundo sem uma nova visão de mundo uma nova lógica de poder, de colaboração solidária." (FREIRE, 2004 apud TOLEDO, FLORES, CONZATTI, 2004, p. 8).

Os autores enaltecem o papel da formação de professores como um dos grandes eixos para ajudar a tornar público o tema cidades educadoras em Porto Alegre.

Consideramos ser esse processo um forte componente da cultura desta cidade, que ajuda a tornar público um tema como esse, a formação dos professores, pela característica de acesso, de divulgação e de universalização de temas de interesse geral do magistério (FISCHER, 2004, p. 57).

Na perspectiva cidadã, Gadotti e Padilha (2004) contribuem trazendo para o debate a escola cidadã e a cidade educadora. Defendem que a origem etimológica dos termos cidadã e cidade é o mesmo, pois derivam da mesma palavra latina civis, que quer dizer cidadão, membro livre de uma cidade a que pertence por origem ou adoção. Logo, civitas designa a comunidade política cujos membros, os cidadãos, autogovernam-se.

Os autores defendem o surgimento de uma escola cidadã no final da década de 80 , início da década de 90, fortemente enraizada no movimento de educação popular e comunitária. Este movimento, na década de 80, se traduziu pela expressão escola pública popular e teve como maior ambição contribuir com a criação de uma nova cidadania; o propósito era a organização da sociedade para a defesa de direitos e a conquista de novos, visando uma mudança do Estado que temos para um Estado radicalmente democrático.

A obra de Gadotti, Padilha e Cabezudo (2004) enaltece aspectos administrativos para que uma Cidade Educadora contemple todos os seus habitantes, os quais usufruam das mesmas oportunidades, sejam formativas, de desenvolvimento pessoal ou de 
entretenimento que a cidade oferece. O município, no processo de tomada de decisões, deverá levar em conta o impacto das necessidades de seus habitantes nas mesmas condições em que a cidade oferecerá aos pais uma formação que lhes permita ajudar seus filhos a crescer e a utilizar a cidade em um espírito de respeito mútuo.

Todos os habitantes da cidade têm o direito de refletir e participar na criação de programas educativos e culturais e a dispor dos instrumentos necessários que lhes permitam encontrar um projeto educativo na estrutura e na gestão da sua cidade, nos valores que esta fomenta, na qualidade de vida que oferece, nas festas que organiza, nas campanhas que prepara, no interesse que manifesta por seus cidadãos e na forma de os escutar.

Gadotti e Padilha (2004) defendem a concepção de que a cidade educadora é uma aprendizagem de planejamento urbano. Assim, a escola e os distintos complexos educacionais, sejam formais, não formais ou informais, existentes nos bairros ou nas vilas, situam-se no contexto da cidade em que se vive; tal contexto designa a aprendizagem que permeia as ações educacionais escolares e designa o projeto político-pedagógico (PPP), o qual pode se transformar em processo fundamental de exercício de cidadania, pois contribui justamente para organizar a intencionalidade educacional necessária para a cidade, de educativa, para, efetivamente, educadora.

Quanto aos territórios educativos, Martinez (2017) procura contribuir para a ampliação da compreensão relacionada à aprendizagem, envolvendo a educação formal, não formal e informal, utilizando-se de todos os espaços oferecidos pela cidade de forma democrática, que tem a educação ambiental como objeto de recorrência.

É signatário que há uma educação ambiental transformadora que possui conteúdo emancipatório, na qual a dialética entre forma e conteúdo se realiza de tal maneira que as alterações da atividade humana, vinculadas ao fazer educativo, implicam mudanças individuais e coletivas, locais e globais, estruturais e conjunturais, econômicas e culturais. Não cabe mais esperar o milagre da mudança de circunstâncias a partir de uma elite intelectual ou econômica ou pela pregação moralista ou ainda pela mudança normativa. O sentido de revolucionar se concretiza como sendo a transformação integral do ser e das condições objetivas de existência em um território educativo, em uma cidade educadora.

No tocante à gestão de cidades educadoras, Alves e Brandenburg (2018) asseveram que o ideal da cidade educadora ratifica o princípio da gestão democrática pontuado pelo 
Estatuto da Cidade, o qual regulamenta os artigos 182 e 183 da Constituição Federal de 1988 e estabelece diretrizes gerais da política urbana.

O referido Estatuto garante a participação popular nas decisões de interesse público e contribui para o processo de planejamento urbano participativo. Encontra suas raízes em históricos clamores populares pelo direito à cidade e considera a participação direta da população em momentos decisórios, tendo como predicado a preponderância de princípios de cooperação e integração referentes à administração, além da politização de questões unidas à justiça social.

Das seis obras que foram relacionadas à educação não formal como eixos principais, três já foram destacadas no estudo anteriormente, quais sejam: as portuguesas de CaballoVillar (2001) e Cabral Pinto (2004), além da dedicada às juventudes nas cidades educadoras, de Carrano (2003). As três obras publicadas que também se alinham à educação não formal, ou seja, preconizam aprendizagens relacionadas à cidade em experiências nas quais os conteúdos não são a priori, mas, sim, construídos no processo, serão mencionadas a seguir.

Biasotto (2006) destaca como a cidade de Dourados no Mato Grosso pode vir a se tornar uma cidade educadora e cumprir com todos os princípios da carta que rege os municípios partícipes da AICE. Afere o nosso mundo de incertezas e este privilegia a procura da segurança que se exprime muitas vezes como a negação e uma desconfiança mútua. A cidade educadora consciente desse fato não procura soluções unilaterais simples, aceita a contradição e propõe processos de conhecimento, diálogo e participação como o caminho adequado à coexistência na e com a incerteza.

Morigi (2016) atesta a mesma condição de Biasotto (2006) e colabora com o entendimento de cidade educadora como um modelo organizativo, à medida que se afasta de uma concepção beneficente e assistencial da ação do município, de ajuda pontual em condescendência dos pedidos que a ele são apresentados. Trata-se de assumir um modelo baseado numa descentralização político-administrativa e num quadro legal de transferência de competências para os municípios, a fim de promover o diálogo entre sociedade civil e estruturas administrativas. Atesta a necessidade da cooperação públicoprivado e a participação do cidadão em uma tentativa de superar fragmentações e duplicações de redes de serviços com vistas à racionalização dos recursos existentes. 
O livro mais antigo que trata da temática, com autoria de Zainko (1997), vem a ser o último mencionado nesse texto. A obra inaugura o tema nas editoras brasileiras, especificamente na Editora da UFPR, em Curitiba. Conforme a autora relata em seu prefácio, a obra tem como objetivo reunir textos notáveis de participantes de um seminário promovido pela Universidade Federal do Paraná, no ano de 1996, com a temática Cidades Educadoras. A autora, protagonista de muitas ações vanguardistas, deixa seu registro na história da cidade e da universidade:

Desafio aceito, organizamos e executamos o Seminário Internacional de Cidades Educadoras Contra a Exclusão e Pela Paz que contou com a presença de renomados especialistas da Espanha, da Itália, da França, de Israel, da Venezuela, do México, de Cuba, da Argentina, do Paraguai, do Uruguai e do Brasil (ZAINKO, 1997, p. 6).

Nessa dianteira, destaca-se o texto de Souza (1997), no qual ainda se utilizam dos termos primeiro e segundo graus, termos substituídos por Ensino Fundamental e Ensino Médio, sendo extremamente atual quando questiona a formação dos professores para educar crianças e jovens desses níveis de ensino e, mais ainda, como serão educados os educadores. Em tempos nos quais não se questionava a formação do formador, lançou essa semente junto à temática de cidades educadoras como eixo para o papel das universidades, especialmente na formação de professores.

\section{CONSIDERAÇÕES FINAIS}

Foi possível depreender desse estudo das 11 obras encontradas publicadas em língua portuguesa um consenso acerca da temática cidade educadora. Não há um conceito fechado e enrijecido que designe o movimento da Associação Internacional de Cidades Educadoras, tampouco quanto aos textos que evocam o conceito de cidades educadoras apesar do movimento espanhol.

É consensual em todos os textos a indicação de que viver a cidade educadora, seja em contexto de educação formal, não formal ou informal, conduz a uma ação dialética de aprendizagem entre sujeito e cidade, cidade e sujeito. Ambos se modificam a partir das marcas que deixam pela vivência, pela pertença, pela intervenção cidadã para a 
modificabilidade dos territórios e dos sujeitos, ambos entrelaçados, pelas aproximações ou distanciamentos que os espaços promovem de experiências.

Uma das obras chega a provocar o movimento de cidades educadoras no sentido de fazê-lo sair da perspectiva educativa para assumir a ação educadora. A cidade educadora é preceptora dos seus sujeitos, os acolhe e os educa, bem como recebe as marcas dessa relação dialética em seus territórios, que necessitam enxergar-se como educativos, portanto, edificantes.

Como todo texto necessita de um ponto-final, este termina com um convite do filósofo dinamarquês Soren Kierkgaard (s.d.) apud Gehl (2015, p. 1) ao enunciar:

Acima de tudo, nunca perca a vontade de caminhar. Todos os dias, eu caminho até alcançar um estado de bem-estar e me afasto de qualquer doença. Caminho em direção aos meus melhores pensamentos e não conheço pensamento algum que, por mais difícil que pareça, não possa ser afastado ao caminhar.

Muitas obras, muitas cidades e muitas experiências ainda permitirão o caminhar dos pesquisadores sobre seus sentidos, suas produções e seus propósitos educadores aos seus sujeitos.

\section{REFERÊNCIAS}

ALVES, Alceli Ribeiro; BRANDENBURG, Elena Justen. Cidades educadoras: um olhar acerca da cidade que educa. Curitiba: InterSaberes, 2018.

BIASOTTO, Wilson Valentim. Edificando a nossa cidade educadora. Dourados: Nicanor Coelho Editor, 2006.

CABALLO VILLAR, Maria Belén. A cidade educadora. Lisboa: Instituto Piaget, 2001. (Coleção O homem e a cidade).

CARRANO, Paulo César. Juventudes e cidades educadoras. Petrópolis: Vozes, 2003.

FISCHER, Nilton Bueno. Autonomia Pedagógica na Cidade Educadora. In: TOLEDO, Leslie; FLORES, Maria Luiza Rodrigues; CONZATTI, Marli (org.). Cidade educadora: a experiência de Porto Alegre. São Paulo: Cortez: Instituto Paulo Freire; Buenos Aires: Ciudades Educadoras America Latina, 2004. (Coleção cidades educadoras).

GADOTTI, Moacir; PADILHA Paulo Roberto. Escola cidadã, cidade educadora: projeto político-pedagógico e práticas em processo. In: GADOTTI, Moacir; PADILHA, Paulo 
Roberto; CABEZUDO, Alicia (org.). Cidade educadora: princípios e experiências. São Paulo: Cortez: Instituto Paulo Freire; Buenos Aires: Ciudades Educadoras America Latina, 2004.

GADOTTI, Moacir; PADILHA, Paulo Roberto; CABEZUDO, Alicia (org.). Cidade educadora: princípios e experiências. São Paulo: Cortez: Instituto Paulo Freire; Buenos Aires: Ciudades Educadoras America Latina, 2004.

GEHL, Jan. Cidades para pessoas. 3. ed. São Paulo: Editora Perspectiva, 2015.

GÓMEZ-GRANELL, Carmen; VILA, Ignacio (org.). A cidade como projeto educativo. Trad. Daisy Vaz de Moraes. Porto Alegre: Artmed, 2003.

MARTINEZ, Roberto. A educação ambiental na cidade educadora. Curitiba: Appris, 2017.

MORIGI, Val ter. Cidades educadoras: possibilidades de novas políticas públicas para reinventar a democracia. Porto Alegre: Sulina, 2016.

PINTO, Fernando Cabral. Cidadania, sistema educativo e cidade educadora. Lisboa: Instituto Piaget, 2004. (Coleção Horizontes Pedagógicos).

ROMANOWSKI, Joana Paulin; ENS, Romilda Teodora. As pesquisas denominadas do tipo “estado da arte". Diálogo Educacional, Curitiba, v. 6, n. 19, p. 37-50, set. 2006.

SOUZA, Marcelo José Lopes. O papel da educação no combate à violência urbana no Brasil: da educação para a cidadania aos limites da educação em uma sociedade injusta. In: ZAINKO, Maria Amelia Sabbag (org.). Cidades educadoras. Curitiba: Editora da UFPR, 1997.

TOLEDO, Leslie; FLORES, Maria Luiza Rodrigues; CONZATTI, Marli (org.). Cidade educadora: a experiência de Porto Alegre. São Paulo: Cortez: Instituto Paulo Freire; Buenos Aires: Ciudades Educadoras America Latina, 2004. (Coleção cidades educadoras).

TRIVIÑOS, Augusto N. S. Introdução à pesquisa em Ciências Sociais. São Paulo: Atlas, 2006.

ZAINKO, Maria Amelia Sabbag (org.). Cidades educadoras. Curitiba: Editora da UFPR, 1997. 